\title{
RASTREABILIDADE: UMA EXIGÊNCIA DA CADEIA AGROINDUSTRIAL PARA PRODUTOS ESPECIAIS
}

\section{TRACEABILITY: A DEMAND OF AGRO INDUSTRIAL CHAIN FOR SPECIAL PRODUCTS}

\author{
José Verissimo Foggiatto Silveira \\ Engenheiro Agrônomo \\ Mestre em Engenharia de Produção pela U.T.F/PR campus Ponta Grossa -PR \\ Av. Anita Garibaldi, 1771, casa 12. CEP: 84015050 - Ponta Grossa - PR \\ Fone: (042)32245855 foggiattojv@hotmail.com
}

\section{Luis Maurício Martins de Resende}

Professor Doutor do Departamento de Pós Graduação do Curso de Engenharia de Produção da U.T.F.PR campus Ponta Grossa - PR

Av. Monteiro Lobato, s/n ${ }^{\circ}-$ Km 04. CEP: 84016-210 - Ponta Grossa - PR

Fone: (042) 32204805 mauricio@pg.cefetpr.br

\section{Luiz Alberto Pilatti}

Professor Doutor do Departamento de Pós Graduação do Curso de Engenharia de Produção da U.T.F/PR campus Ponta Grossa - PR

Av. Monteiro Lobato, s/n ${ }^{\circ}-$ Km 04. CEP: 84016-210 - Ponta Grossa - PR

Fone: (042) 32204805 lapilatti@pg.cefetpr.br

\section{Resumo}

A introdução de produtos agrícolas com características nutricionais diferenciadas tem alterado a relação, a montante e a jusante das empresas que os produzem e comercializam. É necessária uma coordenação no Sistema Agroindustrial introduzindo-se a rastreabilidade, como forma de garantir a conformidade dos produtos, atendendo a clientes externos e agroindústrias que exigem uma certificação da qualidade. Por meio dessa ferramenta de qualidade, são identificados detalhes na cadeia produtiva como sementes, lavoura, colheita, armazenagem, transporte e industrialização do produto. Dessa forma, esse artigo descreve o 
conceito de rastreabilidade e fornece informações de produtos especiais de uma cooperativa paranaense com processo controlado de informações na cadeia produtiva, exigido por parcerias contratuais feitas com empresas fornecedoras de insumos e processadoras de alimentos. Identificou-se que, essa cooperativa transaciona três produtos que necessitam da rastreabilidade: dois tipos especiais de milho e a soja convencional.

Palavras - chave: rastreabilidade, sistema agroindustrial, logística de produção.

\begin{abstract}
The inclusion of agricultural products with different nutritional features has altered the relationship, the upstream and the downstream of enterprises that produce and commercialize them. Coordination in the Agro Industrial System is demanded, including traceability as a way to guarantee the conformity of products, attending external clients and agricultural industries that require quality certification. This quality tool enables the identification of some details in the productive chain, such as seeds, farming, harvesting, storage, transportation and industrialization of products. Thus, this essay describes the concept of traceability and provides information of special products from a cooperative from Paraná, which has controlled process in the productive chain, demanded by contractual partnerships done with enterprises that provide fertilizers and food processors. It was identified that this cooperative commercializes three products that need traceability: two special kinds of corn and the regular kind of soybean.
\end{abstract}

Key words: traceability, agro industrial system, production logistic.

\title{
1. INTRODUÇÃO
}

As preocupações com a segurança dos alimentos e as atuais exigências e tendências dos consumidores ocasionam uma demanda por informações desde a origem da produção até o consumidor final. Esse processo dinâmico que o sistema agroalimentar está sofrendo implica mudanças na organização de toda a cadeia produtiva como forma de agilizar e criar novos produtos exigidos pelo mercado. Tirar proveito comercial da padronização de produtos requer instituições que conduzam os testes e certifiquem os resultados. Entretanto, assegurar e transmitir informações sobre o processo produtivo requer ações coordenadas na cadeia de suprimentos das firmas agroindustriais, implicando mudanças no processo produtivo de 
culturas agrícolas, exigindo estruturas de governança distintas ao sistema agroindustrial (SAG) genérico de tais produtos.

A necessidade de certificação foi evidenciada com o problema recente ocasionado pela doença denominada de "vaca louca" (Bovine Spongiform Encephalopathy - BSE) ocorrido na Europa. Diante desse acontecimento, faz-se urgente um sistema de controle mais rigoroso na segurança alimentar na cadeia da carne bovina.

Da mesma forma, o boicote pelos europeus, aos organismos geneticamente modificados (OGMs) como a soja transgênica, tem ampliado debates com surgimento de segmentos de mercado, sendo a origem do produto e/ou o processo elemento-chave para a diferenciação de bens e agregação de valor.

A agroindústria, como processadora de alimentos, requer um controle rigoroso do processo para obtenção de alguns produtos específicos, vegetais ou animais. Para isso, necessita da certificação de origem para garantia da inocuidade e de preservação das qualidades nutritivas dos alimentos produzidos para os consumidores. Esse processo, de total controle sobre as fases na cadeia produtiva, denomina-se de rastreabilidade, um conceito cada vez mais praticado pela exigência da agroindústria e do próprio cliente consumidor.

Nesse contexto, esse artigo tem por objetivo realizar uma breve revisão sobre o conceito de rastreabilidade e também verificar quais produtos agrícolas provenientes de lavouras de uma cooperativa paranaense exigem a prática desse conceito, como forma de preservar a sua identidade e qualidade para uso na agroindústria.

\section{REVISÃO BIBLIOGRÁFICA}

O termo rastreabilidade não é encontrado no dicionário da língua portuguesa, mas pode-se interpretá-la pela agregação do verbo rastrear que significa seguir o rastro ou pista com a palavra habilidade BASSANI (2002). Na língua inglesa chama-se traceability e na francesa traçabilité.

Pallet (2003) define rastreabilidade como a gestão da informação pela sincronização permanente dos fluxos de mercadoria e informações ligadas. Classifica a rastreabilidade quanto à logística do produto, como a capacidade de segui-lo no tempo e no espaço e quanto ao conteúdo como a capacidade de dar todas as informações sobre a vida desse produto. $\mathrm{O}$ mesmo autor ainda define o princípio da rastreabilidade, como o processo para assegurar a manutenção das características dos alimentos proporcionando segurança e qualidade em todos os seus fluxos de vida. Quanto aos objetivos descreve que, com informações confiáveis 
subsidia uma rotulagem segura, proporcionando confiabilidade aos alimentos. É também uma ferramenta para evidenciar uma qualidade de um produto regional protegendo um mercado cativo ou promissor. Como exemplo de sua aplicação, cita-se a cadeia alimentar em bovinos, suínos, laticínios, frutas, grãos, enfim uma variedade grande de possibilidades.

Informações referentes ao processo, produto e serviços podem ser rastreadas desde a montante até a jusante da cadeia produtiva incluindo internalidades nas empresas. Dessa forma, permite-se realizar um histórico do produto com complexidade definida pelo ambiente que se está trabalhando (VINHOLIS e AZEVEDO, 2002). A exigência externa por informações sobre o produto e o processo de produção é que indicará o grau de rastreabilidade que se pretende trabalhar. Quando o produto é diferenciado ou o consumidor tem necessidade da visualização das informações, a rastreabilidade deve ser realizada ao longo da cadeia.

Essas exigências cada vez mais apuradas dos consumidores por qualidade e variedade de produtos, acarretam uma segmentação de mercado das cadeias produtivas. O segmento agroindustrial não foge a esta tendência, a expansão de variedades de produtos agroalimentares ofertados pela indústria de alimentos nos últimos dez anos demonstra existir nichos de mercado com seus segmentos de consumo (LEONELLI e AZEVEDO, 2002). Os autores informam que assegurar e transmitir informações sobre o processo produtivo invoca ações coordenadas na cadeia de suprimento das firmas agroindustriais, implicando em mudanças nos processos produtivos de grãos e vegetais, demandando estruturas de governança distintas ao do sistema agroindustrial (SAG) genérico de tais produtos que passam agora a ser regidos por contrato.

A Comissão Européia (2001) afirma que, o mercado de produtos obtidos através de sistemas de preservação de identidade tem expectativa de crescimento tanto em número como nichos de mercado, com ou sem a presença de OGMs. Especialistas em mercado estimam em $25 \%$ a cota de mercado para a soja e milho com identidade preservada para 2005. Nos EUA é estimada uma participação de $10 \%$ na produção agrícola com sistemas de identidade preservada, espera-se um incremento de $30 \%$ em dez anos. A preservação da identidade apresenta um custo adicional que deve ser diluído ao longo da cadeia produtiva. Essa mesma comissão informa ainda que, para a preservação da identidade da cultura da canola geneticamente modificada, realizado no Canadá incluindo somente a fase do plantio até a armazenagem, constatou um custo de US\$3,4/ton. Já para a certificação da soja não transgênica nos EUA no ano de 1998 aferiu-se um custo de até US\$3,88/ton. Uma alternativa 
para esses testes dispendiosos é a introdução de genes que indicariam visualmente a identidade do organismo geneticamente modificado.

Em relação aos produtos vegetais segregados e certificados, portanto, produzidos com auxílio da rastreabilidade, que fazem parte de nossa escolha para esse estudo, pode-se citar alguns grupos que exigem esse processo: os produtos orgânicos, não geneticamente modificados, produtos regionais com selo de qualidade e produtos com Indicação Geográfica Protegida (SOUZA e ALCÂNTARA, 2003), (BASSANI, 2002) e (LEONELLI e AZEVEDO, 2002).

Dentre o rol de produtos diferenciados, existem aqueles provenientes da biotecnologia que são chamados de geneticamente modificados e que estão inseridos em discussões polêmicas pela comunidade científica e sociedade em geral. Com esse cenário, são necessários instrumentos de coordenação do sistema agroalimentar para sua segregação (CHADDAD et al, 2002). A soja, incluída nesse contexto de controvérsias, requer um selo de certificação que garanta a sua identidade, essa commodity agrícola deve possuir atributos que a diferencie, com informações intangíveis no produto em si, pois as particularidades no processo de produção devem ser normatizadas e informadas com veracidade (LEONELLI e AZEVEDO, 2002). A soja para receber a certificação é rastreada e analisada por meio de testes que indicam a sua identidade (FUNDEPEC, 2002).

Essas restrições aos produtos transgênicos, alegações fitossanitárias e qualitativas demonstram a necessidade de uma rápida organização das cadeias produtivas no Brasil. A questão específica dos transgênicos, como uma tecnologia de impacto que ainda gera controvérsias, será considerada ao longo do tempo como alternativas qualitativas segregadas. Portanto, o mercado global de alimentos se tornará cada vez mais diversificado e rigoroso quanto à qualidade dos alimentos e, dessa forma, surge uma nova necessidade para estar competitivo e romper barreiras. Como exemplo dessa tentativa, vemos o estado do Paraná que tenta proibir a introdução da soja transgênica para evitar contaminações das suas lavouras convencionais visualizando um nicho que seja valorizado no mercado externo (SILVEIRA et al. 2003).

Outra forma de segmentar e valorizar produtos agrícolas é identificar aqueles produzidos em uma determinada região com características próprias de qualidade. Com esse procedimento, esses produtos regionais são inseridos e valorizados no cenário global através de ações ordenadas para o estabelecimento de uma garantia de qualidade por meio de um rótulo que seja reconhecido (LEADER, 2002). Conforme ainda a LEADER (Liaison entre 
Actions de Développement de L'Économie Rurale), que é um grupo de trabalho dentro da Comissão Européia, a criação de um logotipo, no ano de 1992, permite identificar os produtos agro-alimentares provenientes de sistemas de proteção DOP - Denominação de Origem Protegida ou IGP - Indicação Geográfica Protegida. Esse logotipo possui as cores azul e amarela, com grafismos representando a União Européia, donde se protege e se exalta não somente o produto como toda uma região. Quando produtos ultrapassam as fronteiras de onde são produzidos passam a se defrontar com similares, sofrendo concorrências desleais desencorajando produtores e enganando consumidores.

Segundo Lima (2000), a introdução de variedades de plantas com características nutricionais diferenciadas através de técnicas convencionais de melhoramento genético ou pela biologia molecular, atende setores como indústria de rações e indústria alimentícia em geral. Esses produtos alteram as relações comerciais passando de commodity, isto é, grandes lotes para ingredientes especializados, com características desejadas pelos processadores. Essa mudança recente está valorizando as ações de companhias produtoras de sementes com características qualitativas nutricionais diferenciadas. Os avicultores e suinocultores dos Estados Unidos da América há mais de cinco anos utilizam o ingrediente milho com alto teor de óleo para fornecer aos animais, com isso, conseguiram uma economia de 5\% a $10 \%$ na fabricação das suas rações.

Portanto, com a evolução tecnológica e crescimento de produtos especiais fornecidos por empresas de insumos, principalmente advindos da biotecnologia, surgirão vários produtos com características nutritivas diferenciadas ou com tecnologia de produção que exigem segregação e deverão entrar num processo de rastreabilidade e certificação.

Como exemplo dessa diversificação a transnacional Monsanto (2002) cita alguns projetos:

- $\quad$ Soja e milho com baixo teor de fitato e fitase.

- Baixo teor de estaquiose na soja também conhecido como soja com alto teor de sacarose.

- $\quad$ Soja com alto teor de ácido oléico.

- Milho e soja com alto teor de lisina, metionina e treonina.

- Soja com alto teor de oligofructose

- Soja com alto teor de isoflavona e alto teor de ácido linoleico conjugado (CLA) 
Essa diversificação exige um controle da produção para preservar a identidade de cada produto, para isso utiliza-se a rastreabilidade, que é uma ferramenta para a gestão de toda a informação gerada na cadeia produtiva. O uso dessa rastreabilidade no agronegócio advém de necessidades para a garantia da conformidade do produto, exigências dos consumidores, produtos regionais valorizados e necessidades da agroindústria para preservar a qualidade nutricional de produtos especiais.

Inserindo-se nessa teoria, este artigo descreve quais produtos de uma cooperativa agrícola do Paraná que exigem a rastreabilidade para atender a agroindústria, a montante com empresas fornecedoras de insumos e a jusante com indústrias processadoras de alimentos.

\section{METODOLOGIA}

Esse estudo se fundamentou em uma pesquisa qualitativa, pois, somente procurou-se evidências de relacionamentos comerciais formalizados em contratos para produção de produtos especiais segregados, sem se preocupar com ferramentas estatísticas. Assume a forma de estudo de caso e de levantamento de dados. Os estudos de caso apresentam características de avaliação que permitem explorar os supostos vínculos causais em intervenções da vida real. É a estratégia escolhida ao se examinarem acontecimentos contemporâneos, pois permite observações diretas dos acontecimentos estudados e entrevistas das pessoas neles envolvidos (YIN, 2003).

Como método de coleta de dados utilizou-se de entrevistas individuais com perguntas semi-estruturadas, pois "a entrevista semi-estruturada, ao mesmo tempo em que valoriza a presença do investigador, oferece todas as perspectivas possíveis para que o informante alcance a liberdade e a espontaneidade necessárias, enriquecendo a investigação" (TRIVIÑOS, 1987). Confirmando esse direcionamento Yin (2003) relata que as entrevistas realizadas através de perguntas semi-estruturadas, permite uma maior possibilidade de relatos, opiniões e até de sugestões.

A Cooperativa Castrolanda-Castro-PR foi escolhida por ter relações contratuais com indústrias que adquirem produtos especiais que exigem a rastreabilidade. A pesquisa também foi realizada com o gerente agrícola e o setor comercial dessa Cooperativa, de onde foram coletadas as informações e os dados para compilação. 


\section{RESULTADOS e DISCUSSÃO}

Conforme informações da gerência agrícola dessa cooperativa, atualmente existem três produtos que exigem a rastreabilidade para a certificação. O primeiro e mais antigo, introduzido em escala comercial no ano de 1997, é o milho waxy, pertencente à empresa multinacional DOW-Seeds. O segundo é a soja convencional, portanto, num volume bem maior, para atender à exigência de compradores externos que acenam com uma antagonia dos consumidores pela soja transgênica. O terceiro produto e, mais recente, é o milho MAV, isto é, milho com alto valor nutritivo que é uma variedade de propriedade da empresa produtora de sementes denominada de Dekalb, pertencente à multinacional americana Monsanto. Essa variedade de milho produz alto teor de óleo, acima de 7\% quando os comuns produzem em torno de $4 \%$. O gerente agrícola ainda descreve algumas características desses produtos:

Milho Waxy: esse milho possui alto teor de um tipo de amido chamado de amilopectina que apresenta alto rendimento industrial e é utilizado para amidos especiais. Ë produzido sob a forma de contrato com a indústria National de Santa Catarina. A semente desse material é fornecida pela $D O W$-Seeds e deve ser cultivada de forma isolada, pois, grãos de pólen de variedades comuns interferem nessa característica desejada. Para tanto, a sua rastreabilidade é necessária desde o plantio até a entrega na indústria para evitar contaminação. A rastreabilidade desse produto é realizada em conjunto pelo corpo técnico da cooperativa e da National. A cooperativa recebe um sobrepreço de 51\% em relação ao milho comum, deve-se ressaltar que a variedade utilizada do milho waxy não é tão produtiva quanto o comum, mas mesmo assim compensa a sua produção.

Milho MAV: esse milho com alto teor de óleo é proveniente da Dekalb empresa de propriedade da Monsanto. Da mesma forma, deve ser produzido de uma forma isolada para evitar a contaminação de materiais comuns. Existe uma empresa denominada de Renessen que foi criada para administrar e realizar a rastreabilidade desse produto especial. Ele recebe um sobre-preço de R\$ 0,90 por saco se o teor de óleo for igual ou maior que $7 \%$. A produtividade dessa variedade ainda está sendo avaliada, mas segundo a empresa Dekalb ela é semelhante aos melhores milhos comerciais utilizados.

As empresas fornecedoras das sementes realizam da mesma forma contratos com as indústrias para venda antecipada desse insumo para ser fornecido à cooperativa.

Soja convencional: devido à polêmica da soja transgênica, foi necessária a realização de uma produção segregada. Atualmente trabalham com uma empresa certificadora, a SGS, que 
realiza a rastreabilidade desde a produção até o porto. Atualmente essa cooperativa não recebe soja transgênica, fazendo testes em todas as cargas que chegam à recepção. O sobrepreço pelo do prêmio de comercialização da soja convencional certificada ainda não está evidente, mas por enquanto apenas cobre os custos da certificação.

A preservação da identidade dos grãos de soja é verificada através de testes imunológicos qualitativos (anticorpos) ou por quantitativos PCR (análise do DNA). Na análise por anticorpos, que é o utilizado pela cooperativa, prepara-se um macerado do tecido que se quer analisar, semente, folha ou raiz e mergulha-se nele uma fitinha de papel que possui um anticorpo para a proteína produzida pela planta transgênica, indicando ou não a presença da proteína. O teste baseado na análise do DNA apresenta a vantagem de possibilitar a presença do gene em produtos derivados como farelo e farinhas, pois a proteína pode estar desnaturada.

Desde o início dos trabalhos com a SGS, não foram encontrados lotes com soja transgênica na área de abrangência da Cooperativa Castrolanda. Os prêmios sobre os preços futuros de comercialização da soja convencional certificada ainda não estão evidentes, mas poderá ocorrer uma depreciação nos valores da soja transgênica justificando, portanto, o procedimento de certificação. Conforme ainda a gerência agrícola dessa cooperativa, o prêmio pago para a soja não transgênica apenas cobre os custos para a sua certificação, mas mesmo assim a rastreabilidade é realizada, evitando-se possíveis barreiras e transtornos às suas exportações, já que as restrições aos transgênicos são originadas dos europeus que são os nossos principais consumidores. Essa estratégia de certificação, adotada pela cooperativa, interessou à França através de cooperativas importadoras (CAVAC), e de instituições de pesquisa, como a National Graduate Institute for Food Industries e o Institut Nacional de la Recheche Agronomique. Essas instituições têm realizado visitas a essa cooperativa para conhecer o processo de certificação adotado. Dessa forma, têm confiança para importar grãos e farelo de soja, pois preferem o produto não transgênico.

Em relação a esses produtos o setor comercial dessa cooperativa informa a área plantada na safra 2003/2004 conforme o quadro abaixo:

QUADRO: Área plantada de produtos com rastreabilidade.

\begin{tabular}{|c|c|c|c|}
\hline Milho Waxy & Milho MAV & Milho Comum & Soja Convencional \\
\hline $1.922 \mathrm{ha}$ & $610 \mathrm{ha}$ & $17.501 \mathrm{ha}$ & $52.273 \mathrm{ha}$ \\
\hline
\end{tabular}

FONTE: Cooperativa Agropecuária Castrolanda-Castro-PR, 2004. 
O custo para a realização da certificação da soja, que garante o total controle do processo produtivo, desde a aquisição da semente para o plantio até o embarque da produção no porto, está em torno de US\$ 0,06/saco de $60 \mathrm{Kg}$.

\section{CONSIDERAÇÕES}

Em relação à situação apresentada, verifica-se que são três os produtos agrícolas que necessitam da rastreabilidade, fornecidos pela Cooperativa Castrolanda às indústrias: o milho waxy, milho MAV e a soja convencional. O milho waxy e o milho MAV são produzidos na forma de contrato com compra certa e preços definidos. O serviço para a realização da rastreabilidade do milho waxy e MAV é feito por empresas próprias contratadas pelas indústrias que têm necessidade do controle da qualidade final dos produtos.

A decisão da certificação da soja pela Cooperativa Castrolanda partiu da necessidade de se evitar possíveis barreiras de compradores externos que acenam para possíveis resistências de seus clientes aos produtos transgênicos. Essa certificação da soja é realizada por uma empresa certificadora contratada denominada de SGS.

Analisando-se o quadro acima, verifica-se que a certificação da soja convencional onera o sistema produtivo atual dessa cooperativa em US\$ 162.000, ou US\$ 1,0/ton, considerando o custo já mencionado acima de US\$ 0,06/saco de $60 \mathrm{Kg}$ certificado. Esse valor é bem menor que o verificado no Canadá para a certificação da canola transgênica (US\$ 3,4 /ton) e nos EUA para a certificação de soja não transgênica (US\$ 3,88/ton). Até o momento, os prêmios recebidos pela soja convencional certificada, apenas cobrem os custos para a realização desse processo. O mercado exigente deverá pagar um prêmio que justifique de fato o esforço, praticado por essa cooperativa assim como o estado do Paraná, de certificar e manter a competitividade da soja convencional frente à transgênica.

A cooperativa como elo produtivo central organiza-se com as indústrias através de contrato possibilitando, dessa forma, obter sobrepreços para produtos diferenciados. Como medida preventiva ela realiza a rastreabilidade para certificação da soja, não recebendo o produto quando positivo para transgênico.

Neste segmento de tempo que uma parcela da população mundial exige a soja não transgênica, é prudente e oportuno que a cadeia produtiva no Brasil e nos estados se organizem para segmentar e certificar garantindo assim a integridade da soja que será exportada, garantindo mercados mesmo que não haja bonificação sobre preços. Saber 
aproveitar essa oportunidade, no mínimo garante a presença nesse mercado de commodity cheio de barreiras. Isso se torna importante, principalmente para as empresas agroindustriais, que são afetadas diretamente pelas relações de países com o mercado, e pela criação de blocos econômicos como o MERCOSUL, NAFTA, UEE, e mais recentemente, a tentativa da organização da ALCA.

Estudos mais recentes deverão ser realizados para acompanhar a evolução dos resultados do uso da rastreabilidade como ferramenta de gestão para preservar a qualidade e as informações dos produtos ao longo da cadeia produtiva. Além da necessidade da preservação da identidade de produtos específicos para atender à agroindústria, as empresas de alimentos se confrontarão também com questionamentos sobre a origem, qualidade e o processo para obtenção de seus produtos. Portanto, usar apenas estratégias de conformidade compulsória, isto é, medidas que atendem somente a legislação com qualidade mínima, não mais preenchem os requisitos atuais. Esforços para a realização de uma conformidade voluntária, com objetivos de excelência, devem estar na missão da empresa. Para isso, uma adequação de custos e preços deverá ocorrer, devido a mais um componente que onera a produção que é o processo para obtenção da certificação do produto. Caso o mercado não pague mais pela qualidade fornecida, ajustes de custos internos devem ser praticados.

O uso de estratégias como a rastreabilidade para a preservação da identidade de um produto, focadas em nichos de mercado e consumidores podem refletir em maiores ganhos na cadeia produtiva. Para isso, e antes de tudo, esse mercado deve ser criteriosamente avaliado antes de se efetuar qualquer logística de produção. Quando a opção adotada é por mercados focados, surgem riscos inerentes ao método, podendo trazer frustrações e prejuízos.

Portanto, o sistema agroalimentar deve cada vez mais se organizar, pois vários produtos diferenciados se originarão provenientes principalmente da biotecnologia. Novas exigências técnicas, políticas e de consumidores estão se formando, sendo necessária a rastreabilidade de produtos para certificação de todo o processo produtivo, com informações desde a semente até o processamento industrial, visando a produtos de qualidade para a confiança do consumidor final.

\section{REFERÊNCIAS}

BASSANI, C.B. Um Modelo de Rastreabilidade na Industrialização de Produtos Derivados de Suínos. 2002. 94 p. Dissertação (Mestrado em Ciência da Computação) - Programa de Pós 
Graduação em Ciência da Computação, Universidade Federal de Santa Catarina, Florianópolis - SC.

CHADDAD, F.R. Gestão de Negócios em Alimentos. São Paulo - SP: Editora Pioneira Thomson Learning Ltda., 2002. 129 p.

COMISSÃO EUROPÉIA (2001). Designações de Produtos Registrados.

Disponível em: www.europa.eu.int/comm/agriculture/qual/pt/prod pt.htm Acesso em 15 de novembro de 2003.

FUNDEPEC. Relatório Especial do Fundo de Desenvolvimento da Agropecuária do Estado do Paraná, 2002. 16 p.

LEONELLI, F. C. V.; AZEVEDO, P. F. de. Sistemas de Identidade Preservada em Cadeias Agroindustriais: o caso de produtos não geneticamente modificados. Departamento de Engenharia de Produção - UFSCar - SP, 2002.

LEADER. Liaison entre Actions de Développement de L’Économie Rurale. A Competitividade dos Territórios Rurais à Escala Global. Caderno 6, Fascículo 5, 2002.

LIMA, G.J.M.M. (2000) - A Competitividade da Avicultura e Suinocultura depende da Qualidade Nutricional do Milho. Disponível em: >www.embrapa.br> Acessado em 09 de abril de 2004.

MONSANTO. Para Você Ver como a Biotecnologia Aumenta a Lucratividade: você já está ficando rico em informação. Material publicitário, 2003.

PALLET, D. (2003) - Considerações sobre a Rastreabilidade dos Alimentos.

Disponível em: >www.pallet@cendotec.org.br>

Acessado em 16 de março de 2004.

SILVEIRA, J. V. F.; RESENDE, L. M. M.; LEITE, M. Vantagem Competitiva no Setor Agroindustrial: o caso dos transgênicos. In: SIMPOI, 2003, São Paulo. Anais... São Paulo: FGV-EAESP, 2003. 1 CD, n. 309. 
SOUZA, A.P.de O. e ALCÂNTARA, R. L. C. Alimentos Orgânicos: Estratégias para o Desenvolvimento do Mercado in: Marketing e Estratégia em Agronegócios e Alimentos. São Paulo - SP: Editora Atlas S.A., 2003. 365 p.

TRIVIÑOS, A. Introdução à pesquisa em ciências sociais: a pesquisa qualitativa em educação. São Paulo - SP: Atlas. 1987. p. 146.

VINHOLIS, M. de M.B. e AZEVEDO, P. F. de Efeitos da Rastreabilidade no Sistema Agroindustrial da Carne Bovina Brasileira. Grupo de Estudos e Pesquisas em Trabalho, Agroindústria e Políticas Públicas: Departamento de Engenharia de Produção - UFSCar - SP, 2000 .

YIN, R. K. Estudo de Caso - Planejamento e Métodos. Porto Alegre - RS: Editora Bookman. 2003. 212 p. 